\title{
MUDANÇAS PÓS-FOGO NA FLORÍSTICA E ESTRUTURA DA VEGETAÇÃO ARBÓREO- ARBUSTIVA DE UM CERRADO SENTIDO RESTRITO EM PLANALTINA - DF
}

\author{
CHANGINGS AFTER FIRE IN FLORISTIC AND STRUCTURE OF TREE (ARBOREAL AND \\ SHRUB VEGETATION IN A CERRADO SENSU STRICTO IN PLANALTINA, FEDERAL DISTRICT
}

\author{
Mary Naves da Silva Rios ${ }^{1}$ José Carlos Sousa-Silva ${ }^{2}$ Juaci Vitória Malaquias ${ }^{3}$
}

\begin{abstract}
RESUMO
O monitoramento da vegetação arbóreo-arbustiva foi realizado em parcelas permanentes, em duas áreas de Cerrado sentido restrito em Planaltina - DF, em sete ocasiões de 1988 a 2012. Em uma área, Área 1, foram aplicadas queimadas bienais, em agosto de 1988, 1990 e 1992; a outra área, Área 2, foi protegida até julho de 1994, antes do fogo acidental que atingiu as duas áreas em agosto. As áreas foram protegidas da ação do fogo de setembro de 1994 a 2012. Antes das queimadas, foram medidas a circunferência, a $30 \mathrm{~cm}$ do solo, e a altura de todos os indivíduos arbóreo-arbustivos que atingiam um metro ou mais; em 1988, foi medida a altura apenas. A riqueza foi comparada entre as duas áreas. A diversidade de espécies foi analisada por meio dos perfis de diversidade e a similaridade florística, pelo método UPGMA. Foram avaliados os parâmetros de densidade, frequência, dominância e Índice de Valor de Importância. O fogo não influenciou a riqueza de espécies nas duas áreas, em todo o período. Foram registradas 82 espécies nas duas áreas durante todo o período de estudo, sendo, na Área 1, 74 espécies, em 35 famílias, e na Área 2, 73 espécies, em 34 famílias. De 1988 a 1994, as duas áreas apresentaram diferenças na diversidade e na similaridade florística. Após 18 anos de proteção, em 2012, as duas áreas mostraram similaridade florística, porém, diferenças na diversidade, com maior diversidade na Área 1. A comunidade arbóreo-arbustiva mostrou-se resistente e resiliente ao fogo. As queimadas bienais reduziram a densidade e a área basal, mas a exclusão do fogo favoreceu o aumento desses parâmetros nas duas áreas. As distribuições dos indivíduos em classes de altura e de diâmetro não diferiram significativamente, nas duas áreas, mas o fogo afetou, principalmente, os indivíduos nas menores classes de altura e de diâmetro.
\end{abstract}

Palavras-chave: fogo; Cerrado; florística; fitossociologia.

\section{ABSTRACT}

The monitoring of the tree-shrub Cerrado sensu stricto was conducted in two permanent plots, 1.25 ha each, in Planaltina, Federal District, Brazil from 1988 to 2012 throughout seven times. Fire was set in August biennially in Area 1 in 1988, 1990 and 1992. Area 2 was protected against fire until July 1994. There was an accidental burning in August 1994 in both areas, thereafter they were protected against fire until 2012. The diameter and height of trees and shrubs above or equal $1 \mathrm{~m}$ height were measured before fire setting. In 1988, it was measured only the height. The species diversity was analyzed by UPGMA. Density, frequency, dominance and floristic similarity were evaluated. Eighty-two (82) species were recorded in both areas, where 74 species, in 35 families, occurred in Area 1 and, 73 species, in 34 families, in Area 2. From 1988 to 1994 , both areas presented differences in the diversity and in the floristic similarity. In 2012, both areas showed floristic similarity, but the diversity was greater in Area 1. The tree-shrub vegetation was resistant and resilient to fire. Fire reduced the density and the basal area, but when fire was absent, both of them increased. Distributions of living plants in height and diameter classes did not differ significantly in both

1 Engenheira Florestal, Dr ${ }^{\mathrm{a}}$., Programa de Pós-Graduação em Ciências Florestais, Universidade de Brasília, Campus Universitário Darcy Ribeiro, CEP 70910-900, Brasília (DF), Brasil.mnavesrios@gmail.com

2 Biólogo, Ph.D., Pesquisador da Embrapa Cerrados, Rod. BR-020, Km 18, CEP 73310-970, Planaltina (DF), Brasil. jose.sousa-silva@embrapa.br

3 Estatístico, MSc., Analista em Estatística da Embrapa Cerrados, Rod. BR-020, Km 18, CEP 73310-970, Planaltina (DF), Brasil. juaci.malaquias@embrapa.br

Recebido para publicação em 13/11/2015 e aceito em 11/05/2017

Ci. Fl., v. 28, n. 2, abr. - jun., 2018 
areas. Fire affects primarily individuals in the smaller classes of height and diameter.

Keywords: fire; Cerrado; floristics; phytosociology.

\section{INTRODUÇÃO}

O fogo, um dos fatores determinantes da vegetação do Cerrado (FELFILI et al., 2000; MIRANDA; NASCIMENTO NETO; NEVES, 2010), é capaz de afetar a sobrevivência, o crescimento, o estabelecimento de plântulas e indivíduos jovens, a reprodução sexual e vegetativa, com implicações na dinâmica de populações e de comunidades (HOFFMANN, 1996). E com isso, modifica a florística e a estrutura da vegetação (MEDEIROS; MIRANDA, 2005; LIBANO; FELFILI, 2006), podendo, ainda, reduzir a biomassa vegetal e a serapilheira, alterar os fluxos de energia, nutrientes e água (MEDINA; SILVA, 1990; MEDEIROS; MIRANDA, 2005), e criar habitat favorável à invasão de espécies exóticas (SILVA et al., 2011). Os impactos do fogo na vegetação dependem de fatores como época (SATO et al., 2010), tipo, regime de queima e comportamento do fogo (MIRANDA; NASCIMENTO NETO; NEVES, 2010), e da formação vegetacional atingida (CAMARGOS et al., 2015). No Cerrado, as plantas respondem de diferentes formas aos incêndios (MOREIRA, 2000), sendo que algumas, tanto herbáceas quanto lenhosas, possuem estratégias tornando-as mais resistentes. São exemplos dessas estratégias: a suberização do tronco e ramos, permitindo isolamento térmico dos tecidos internos; proteção das gemas apicais pelos catáfilos; presença de órgãos subterrâneos (bulbos, ramos subterrâneos, rizomas e xilopódio) (COUTINHO, 1990; MEDEIROS; MIRANDA, 2008); frutos com proteção das sementes (CIRNE; MIRANDA, 2008); e a capacidade de rebrota da copa, rizomas, caule e outras estruturas subterrâneas (COUTINHO, 1990).

Monitoramentos ao longo do tempo têm demonstrado que a vegetação do Cerrado é resiliente ao fogo (FELFILI et al., 2000) e responde de formas diferentes à eliminação ou intensificação desse distúrbio (LIBANO; FELFILI, 2006; ALMEIDA et al., 2014). A incidência de fogo pode excluir algumas espécies sensíveis, favorecer outras mais resistentes a ele (MOREIRA, 2000; SILVA et al., 2011), reduzir a diversidade, frequência e densidade de espécies lenhosas, aumentar o entouceiramento (FIEDLER et al., 2004), reduzir o recrutamento de plântulas e indivíduos jovens levando a uma interrupção ou estabilização do desenvolvimento da vegetação (HENRIQUES; HAY, 2002). Após o distúrbio, pode haver uma fase de imigração de espécies, com aumento do número de indivíduos e da área basal, e depois uma fase de equilíbrio nas taxas de imigração (recrutamento) e extinção (mortalidade) (HENRIQUES, 2005). A exclusão do fogo favorece a camada lenhosa, dando condições para espécies sensíveis ao fogo se desenvolverem (FELFILI et al., 2000; SILVA et al., 2011), diminui a mortalidade e rotatividade de plantas e eleva as taxas de recrutamento (HENRIQUES; HAY, 2002), com a regeneração de algumas espécies e incrementos em densidade e área basal (FELFILI et al., 2000).

As queimadas têm sido amplamente estudadas (FIEDLER et al., 2004; LIBANO; FELFILI, 2006; RIBEIRO et al., 2012). No entanto, ainda é preciso avaliar as mudanças da vegetação ao longo do tempo para entender os processos e mecanismos que mantêm a comunidade (PINHEIRO; DURIGAN, 2009). Pesquisas relacionadas a mudanças temporais, com histórico de fogo, na florística e na estrutura de comunidades arbóreas e arbustivas do Cerrado são essenciais para o conhecimento da diversidade, estabilidade e dinâmica da comunidade, além de possibilitar o estabelecimento de estratégias para conservação, uso sustentável e recuperação desse bioma. Este estudo teve como objetivos analisar e comparar a composição florística, riqueza e diversidade, bem como as mudanças na estrutura da vegetação arbóreo-arbustiva de um fragmento de Cerrado sentido restrito, em duas áreas, uma com queimadas bienais e a outra protegida do fogo, no período de 1988 a 1994, e com 18 anos de proteção, em 2012. Assim, procurou-se responder às seguintes perguntas: 1) Áreas com distintos históricos de fogo, em um período de seis anos, apresentam diferenças na riqueza, diversidade e estrutura da comunidade? 2) A proteção por 18 anos, de áreas com diferentes históricos de fogo, favorece o aumento da riqueza, da diversidade e a similaridade florística da comunidade? 3) A proteção por 18 anos favorece o aumento da densidade e área basal, confirmando resistência e resiliência da comunidade? 


\section{MATERIAL E MÉTODO}

\section{Área de estudo}

O estudo foi desenvolvido em um fragmento de Cerrado sentido restrito na Reserva Cerrado da Embrapa Cerrados, coordenadas $15^{\circ} 38^{\prime} \mathrm{S}$ e $47^{\circ} 43^{\prime} \mathrm{W}$, datum horizontal Córrego Alegre - MG (PARRON et al., 1998). A reserva fica a nordeste do Distrito Federal, em Planaltina. O solo é do tipo Latossolo Vermelho, textura muito argilosa, relevo plano a suave ondulado, fase cerrado (Typic haplustox), desenvolvido a partir da decomposição da cobertura detrítico-laterítica de caráter argiloso do Terciário. O clima é caracterizado como Aw na classificação de Köppen, com uma estação seca de 5 meses, precipitação média anual de 1.577 $\mathrm{mm}$, temperatura média anual de $20,4^{\circ} \mathrm{C}$, temperatura máxima média de $26,6^{\circ} \mathrm{C}$, e mínima média de $15,8^{\circ} \mathrm{C}$, com altitude de $1.100 \mathrm{~m}$ (SPERA et al., 2000).

\section{Amostragem e coleta dos dados}

A área do estudo, com 2,5 hectares foi dividida em Área 1 e Área 2. Em cada área de cerca de 1,25 ha foram demarcadas duas transecções com 100 metros de comprimento e 10 metros de largura, distanciadas 10 metros entre si, totalizando quatro transecções. As parcelas (MORO; MARTINS, 2011) demarcadas ao longo das transecções, nas dimensões de $20 \mathrm{~m}$ x $10 \mathrm{~m}$, em maio de 1988, foram remarcadas em 1990 no mesmo local, mas com medidas de $10 \mathrm{~m}$ x $10 \mathrm{~m}\left(100 \mathrm{~m}^{2}\right)$, para facilitar os trabalhos de campo. Assim, a partir desse ano, o monitoramento foi feito em 20 parcelas, com área de amostragem de 0,2 hectares em cada área. O local não teve registro de incêndio de 1978 a 1988. As queimadas bienais, mais comuns na região do Cerrado (COUTINHO, 1990), foram aplicadas na Área 1 em 1988, 1990 e 1992, em agosto. As duas áreas foram atingidas por um incêndio em agosto de 1994, mas depois foram protegidas de setembro de 1994 a 2012.

O monitoramento da vegetação, com início em 1988, foi feito sempre antes do fogo, em sete ocasiões (1988, 1990, 1991, 1992, 1993, 1994, 2012), em junho-julho, de 1988 a 1994, e em setembro de 2012. Todas as espécies arbóreo-arbustivas que atingiam o critério de inclusão de um metro ou mais de altura (MUELLER-DOMBOIS; ELLEMBERG, 1974) foram numeradas com placas de alumínio e mensuradas. Em cada parcela, anotaram-se, para cada indivíduo, a altura, a circunferência e o nome da espécie. Também foram incluídos os indivíduos mortos que "estavam em pé" e as espécies da família Arecaceae e do gênero Vellozia que atingiam a altura mínima. A altura total foi medida com uma régua graduada de três metros, sendo a altura acima de três metros estimada visualmente, tomando como base a régua. Em 1988 foram anotados somente os dados referentes à altura. Nos anos de 1990 a 1994 e em 2012, foram medidas altura e circunferência. A circunferência foi medida com fita métrica, a $30 \mathrm{~cm}$ do solo, altura considerada padrão em vários estudos no Cerrado (ALMEIDA et al., 2014). Quando o exemplar de uma espécie se ramificava abaixo do nível do solo e cada eixo emergia separado dos demais, cada eixo foi considerado um indivíduo distinto (MORO; MARTINS, 2011). Nos casos em que os indivíduos apresentavam bifurcações abaixo de $30 \mathrm{~cm}$, mediram-se todos os ramos e, calculou-se o diâmetro quadrático das ramificações com a fórmula de Scolforo e Thiersch (2004):

$$
d=\sqrt{\left(d_{1}\right)^{2}+\left(d_{2}\right)^{2}}
$$

Em que: = diâmetro quadrático; $d_{1}=$ diâmetro do ramo $1 ; d_{2}=$ diâmetro do ramo 2 .

As coletas de material botânico fértil foram depositadas nos Herbários da Universidade de Brasília (UB), Ezechias Paulo Heringer (HEPH), da Reserva Ecológica do IBGE e da Embrapa Recursos Genéticos e Biotecnologia (CENARGEN - CEN), no Distrito Federal.

\section{Análise dos dados}

A lista de espécies foi feita de acordo com APG III - The Angiosperm Phylogeny Group (CHASE; REVEAL, 2009). As espécies foram identificadas por meio de consultas a especialistas, literatura e comparação com exsicatas de Herbários. Para a conferência dos nomes científicos foi consultada, 
principalmente, a Lista de Espécies da Flora do Brasil (JARDIM BOTÂNICO DO RIO DE JANEIRO, 2015). A composição florística foi comparada nas diferentes ocasiões de amostragem. Para verificar se houve diferença entre a riqueza de espécies ao longo do tempo entre as duas áreas, os resultados em cada área foram comparados pelo teste de t pareado (ZAR, 2009) no período de 1988 a 1994 e 2012. A riqueza de espécies de cada área também foi comparada aos pares, por meio do teste de $\chi^{2}$ (SOKAL; ROHLF, 2009) utilizando o software Excel 2010. A diversidade de espécies entre as duas áreas foi comparada empregando Perfis de Diversidade e a série exponencial de Rényi (TÓTHMÉRÉSZ, 1995), no programa PAST 2.15 (HAMMER; HARPE; RYAN, 2001). Com isso foi possível observar graficamente a diversidade com diferentes pesos dados às espécies raras (LEINSTER; COBBOLD, 2012).

A análise de similaridade florística entre as duas áreas e ao longo do tempo empregou o método de Ligação Média Não Ponderada (UPGMA), que expressa, por meio de um dendrograma, as relações de similaridades entre as áreas, com base na presença e ausência das espécies, usando o índice de Jaccard (VALENTIN, 2000). O coeficiente de correlação cofenética avaliou o grau de distorção entre a matriz de similaridade e o dendrograma; quanto mais próximo de 1, menor o grau de distorção (VALENTIN, 2000). $\mathrm{Na}$ descrição da comunidade foram calculados os parâmetros de Frequência, Densidade, Dominância e Índice de Valor de Importância (IVI), para o período de 1990 a 1994 e 2012, incluindo também os indivíduos que rebrotaram na base do caule ou de estruturas subterrâneas com altura acima de $30 \mathrm{~cm}$. Nas análises utilizou-se o programa FITOPAC 2.1 (SHEPHERD, 2010). As distribuições dos indivíduos em classes de altura e diâmetro foram feitas usando a equação de Sturges, proposta por Spiegel e mencionada por Felfili e Rezende (2003):

$$
\mathrm{IC}=\frac{\mathrm{A}}{\mathrm{nc}} ; \mathrm{nc}=1+3,3 \log (\mathrm{n})
$$

Em que: IC= intervalo de classe; $\mathrm{A}=$ amplitude (valor máximo - valor mínimo); nc = número de classes; $\mathrm{n}=$ número de indivíduos.

Foram construídos histogramas de frequência com intervalos de classes de diâmetro de 5,3 e de altura de 1,2 para os indivíduos registrados nas duas áreas, de 1988 a 2012. Em 1988, as análises foram feitas somente com dados de altura, pois, nesse ano, o diâmetro não foi mensurado. Na elaboração dos histogramas em classes de diâmetro, nos anos em que ocorreram rebrotas, foram incluídas somente aquelas com altura maior que $30 \mathrm{~cm}$. Já os histogramas em classes de altura incluíram todos os indivíduos. Para analisar se a distribuição dos indivíduos vivos, em classes de diâmetro e altura, variou ao longo do tempo, nas duas áreas, foi aplicado o teste não paramétrico de Kolmogorov-Smirnov (ZAR, 2009), a 5\% de significância, pareando as amostras a cada dois anos, no programa PAST 2.15 (HAMMER; HARPE; RYAN, 2001). As mudanças estruturais na densidade, de 1988 a 2012, e na área basal, de 1990 a 2012, foram avaliadas pelo teste de $t$ de Student e teste de t pareado (ZAR, 2009), no software Excel 2010, do Windows. Os dados foram transformados em raiz quadrada a fim de reduzir a variabilidade, avaliando-se se os valores atendiam aos pressupostos de normalidade e de homocedasticidade.

\section{RESULTADOS E DISCUSSÃO}

Os resultados do monitoramento no período com queimadas bienais, de 1988 a 1994, e após 18 anos sem fogo, em 2012, evidenciaram mudanças em relação à composição florística e à estrutura da comunidade arbóreo-arbustiva. O número de indivíduos vivos e de espécies variou tanto na Área 1 quanto na Área 2, nas diferentes ocasiões (Tabela 1). A proteção por 18 anos favoreceu o aumento da abundância nas duas áreas, sendo 1288 na Área 1 e 1206 na Área 2. 
TABELA 1: Número de indivíduos, famílias, gêneros e espécies em duas áreas de Cerrado sentido restrito com diferentes históricos de fogo, em Planaltina, Distrito Federal (DF), em sete ocasiões no período de 1988 a 2012.

TABLE 1: Number of individuals, families, genus and species in two areas of Cerrado sensu stricto with different historical burnings in Planaltina, Federal District, Brazil, on seven occasions from 1988 to 2012.

\begin{tabular}{cccccccccccccccc}
\hline Parâmetros & \multicolumn{1}{c}{1988} & \multicolumn{1}{c}{1990} & \multicolumn{1}{c}{1991} & \multicolumn{1}{c}{1992} & \multicolumn{1}{c}{1993} & \multicolumn{3}{c}{1994} & \multicolumn{3}{c}{2012} \\
\cline { 2 - 15 } & $\mathrm{A} 1$ & $\mathrm{~A} 2$ & $\mathrm{~A} 1$ & $\mathrm{~A} 2$ & $\mathrm{~A} 1$ & $\mathrm{~A} 2$ & $\mathrm{~A} 1$ & $\mathrm{~A} 2$ & $\mathrm{~A} 1$ & $\mathrm{~A} 2$ & $\mathrm{~A} 1$ & $\mathrm{~A} 2$ & $\mathrm{~A} 1$ & $\mathrm{~A} 2$ \\
\hline Indivíduos & 656 & 509 & 383 & 783 & 446 & 790 & 490 & 812 & 476 & 910 & 471 & 924 & 1288 & 1206 \\
Famílias & 31 & 30 & 31 & 31 & 30 & 29 & 30 & 29 & 30 & 29 & 30 & 29 & 33 & 32 \\
Gêneros & 48 & 45 & 43 & 49 & 42 & 45 & 42 & 44 & 42 & 46 & 42 & 45 & 54 & 53 \\
Espécies & 54 & 49 & 49 & 56 & 49 & 50 & 49 & 49 & 49 & 51 & 49 & 50 & 68 & 63 \\
\hline
\end{tabular}

Em que: A1 = Área 1, com aplicação de queimadas em 1988, 1990 e 1992, e proteção de setembro de 1994 a 2012; A2 = Área 2, protegida contra o fogo de 1988 a julho de 1994, e de setembro de 1994 a 2012; fogo acidental nas duas áreas em agosto de 1994.

Na Área 1, o tratamento com fogo levou a uma redução no número de indivíduos, que foi inferior ao encontrado em 1988 em todos anos de 1990 até 1994. Em 1990, esse número reduziu de 656 para 383 indivíduos na Área 1 e aumentou de 509 para 783 na Área 2. Em 1994, antes do fogo acidental, que afetou as duas áreas em agosto, havia 471 indivíduos na Área 1 e 924 na Área 2. Assim, comparado com 1988, após 3 queimadas bienais, o número de indivíduos reduziu em 28,2\% na Área 1, e aumentou em 81,5\% na Área 2. A área ficou sem queimar desde 1978; com a queimada de 1988, possivelmente, a redução dos indivíduos em 1990 pode ter sido em função da eliminação ou diminuição das espécies sensíveis ao fogo e maior dominância daquelas mais resistentes (SAMBUICHI, 1991). Em outra área de Cerrado sentido restrito, no Distrito Federal, Almeida et al. (2014) também relacionaram a redução no número de indivíduos, após a passagem do fogo, à presença de algumas espécies sensíveis ao distúrbio.

Fabaceae foi a família com maior abundância, na Área 1, de 1988 a 1994, e Nyctaginaceae, em 2012. Na Área 2, Fabaceae foi a família mais abundante, de 1988 a 1992, e Primulaceae, em 1993, 1994 e 2012. A família Fabaceae, mais rica em espécies nas duas áreas, tem sido mencionada entre as mais importantes no bioma Cerrado, concordando com outros estudos no Distrito Federal (FIEDLER et al., 2004; ALMEIDA et al., 2014). Nas duas áreas, foram registradas 82 espécies durante o período de estudo, sendo que, na Área 1, foram 74 espécies, em 58 gêneros e 35 famílias, e na Área 2, 73 espécies, em 58 gêneros e 34 famílias (Tabela 1). O total de espécies, variando de 49 a 68, durante o monitoramento, está de acordo com o mencionado para o Cerrado sentido restrito no Distrito Federal (ASSUNÇÃO; FELFILI, 2004; ALMEIDA et al., 2014). Em 1988, eram 54 espécies (31 famílias, 48 gêneros), na Área 1, e 49 espécies (30 famílias, 45 gêneros) na Área 2. Em 2012, havia 68 espécies (33 famílias, 54 gêneros) na Área 1 e 63 espécies ( 32 famílias, 53 gêneros) na Área 2. E, dentre todas as espécies, 13 foram representadas por apenas um indivíduo, em pelo menos um dos levantamentos (de 1988 a 2012), na Área 1, e 26 na Área 2.

A riqueza de espécies se manteve ao longo do período com queimadas, de forma que algumas espécies foram excluídas e outras incluídas, mas houve a manutenção da maioria; das 54 espécies observadas em 1988, oito foram excluídas, mas outras três incluídas em 1990. E, das 74 espécies registradas em todo o período, 45 se mantiveram em todos os anos e 13 apareceram em 2012. Na Área 2, das 73 espécies, 44 ocorreram todos os anos e 14 apareceram em 2012. A entrada de novas espécies foi registrada nas duas áreas em 2012 indicando alta resiliência da comunidade frente ao distúrbio. Em outro estudo, Henriques e Hay (2002) também verificaram aumento no número de espécies, além de gêneros e famílias e alta taxa de imigração em Cerrado sentido restrito, protegido do fogo, no Distrito Federal. A manutenção da riqueza, com saída e entrada de espécies e com modificações relacionadas aos eventos de fogo, também foi registrada em Cerrado sentido restrito na Fazenda Água Limpa/UnB (DF), na qual, das 69 espécies, 52 foram comuns em 18 anos (LIBANO; FELFILI, 2006). Dessa forma, os resultados sugerem que, mesmo diante de queimadas frequentes, tem-se a manutenção e a entrada de algumas espécies, principalmente, daquelas menos sensíveis ao distúrbio.

Quanto à diversidade, o perfil de diversidade mostrou maior diversidade na Área 2, em 1988 (Figura 
1B), em relação à Área 1, possivelmente, em decorrência da heterogeneidade florística frequentemente relatada em outros estudos em Cerrado sentido restrito (CARVALHO et al., 2008), ou dos efeitos da fragmentação (SCARIOT et al., 2003). No período de 1990 a 1994, na Área 1, a sobreposição das curvas mostrou diversidade similar e indicou que, apesar do fogo frequente, manteve-se a diversidade da comunidade. Na Área 2, nesse mesmo período, também houve sobreposição das curvas e diversidade similar, porém, maior dominância e menor equabilidade. Diante desses resultados, cabe enfatizar que o fogo pode reduzir a dominância de plantas estabelecidas, favorecer o estabelecimento de algumas espécies (HOFFMANN, 1996) e eliminar espécies sensíveis ao distúrbio (SAMBUICHI, 1991). Assim, as queimadas bienais podem ter favorecido espécies resistentes e eliminado aquelas mais sensíveis, ocasionando baixa dominância de espécies e maior equabilidade, o que tornou as duas áreas diferentes em diversidade, mas com a manutenção da diversidade de cada área. Em Cerrado sentido restrito, em Nova Xavantina - MT, Lima, Lima e Ratter (2009) também observaram pouca influência do fogo na diversidade. E, quanto à manutenção da diversidade, essa também foi constatada em duas áreas de Cerrado sentido restrito com diferentes frequências de fogo, por Ribeiro et al. (2012), em Barra do Garças - MT. Em Planaltina (DF), após 18 anos de proteção, em 2012, as duas áreas também apresentaram diferenças na diversidade, sendo menor na Área 2, que teve maior dominância de espécies e menor uniformização das abundâncias. Nesse ano, os diferentes históricos de fogo das duas áreas, o pisoteio esporádico do gado bovino, com a invasão de gramíneas exóticas, e a pressão antrópica do entorno podem ter influenciado as respostas da comunidade, tornando as áreas diferentes em diversidade.
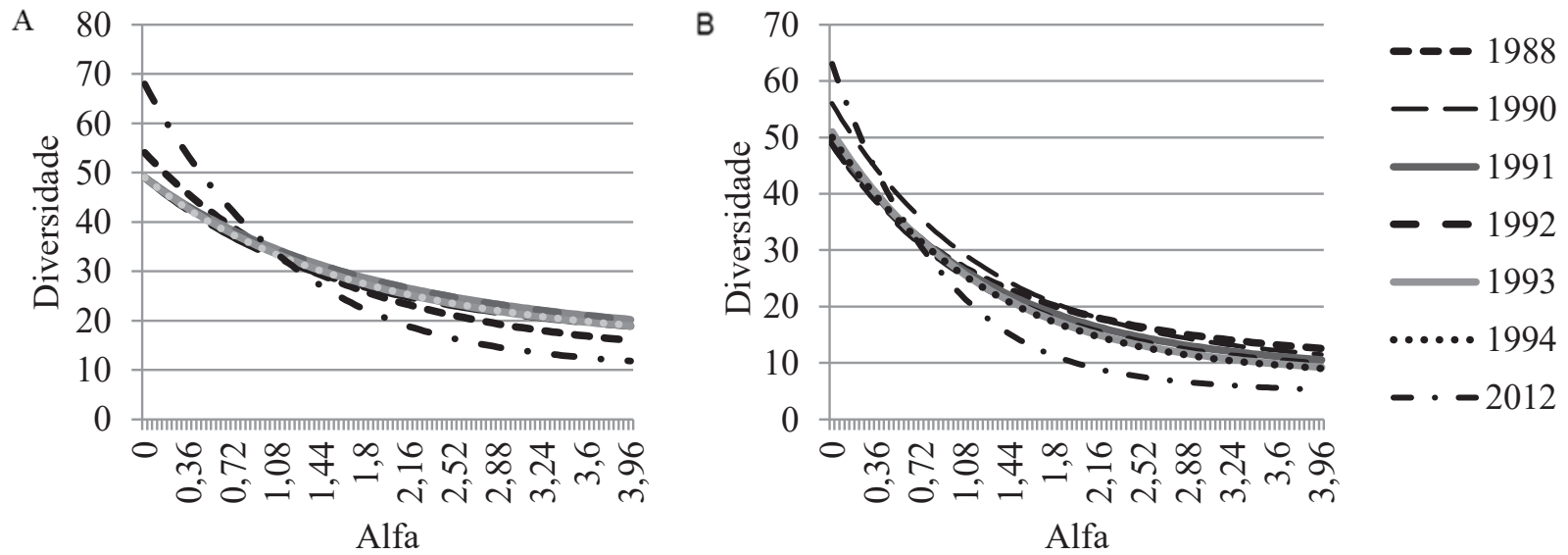

FIGURA 1: Perfil de diversidade em duas áreas de Cerrado sentido restrito em Planaltina - DF no período de 1988 a 1994 e em 2012. Em que: A = Área 1, com três queimadas bienais de 1988 a 1992; B = Área 2, protegida do fogo de 1988 a julho de 1994; e com proteção das duas áreas de setembro de 1994 a 2012.

FIGURE 1: Diversity profile in two areas of Cerrado sensu stricto with different historical burnings in Planaltina, Federal District, Brazil, from 1988 to 1994 and 2012. Where: A = Area 1, fire was set in 1988, 1990 and 1992; B = Area 2, was protected against fire from 1988 to July 1994; and both areas were protected against fire from September 1994 to 2012.

A análise de agrupamento, pelo índice de Jaccard, nos diferentes anos de monitoramento, indicou a formação de 3 grupos distintos (Figura 2). O Grupo A foi formado pela Área 1 (de 1988 a 1994), o Grupo B pela Área 2 (de 1988 a 1994) e o Grupo C pela Área 1 e Área 2, em 2012. Houve diferenças na similaridade qualitativa entre a Área 1 e a Área 2, de 1988 até 1994. No entanto, com a proteção por 18 anos, essas áreas tornaram-se similares quanto à composição das espécies. Em outra área de Cerrado sentido restrito, no Distrito Federal, com três queimadas, em um período de 18 anos, Libano e Felfili (2006) também observaram alta similaridade qualitativa. Assim, os resultados alcançados na Embrapa Cerrados e os encontrados por Libano e Felfili (2006) demonstram que, mesmo com as queimadas frequentes, a exclusão do distúrbio possibilita o retorno de algumas espécies e, com isso, a manutenção da composição florística. As queimadas frequentes reduziram a densidade da comunidade, contudo, o período de exclusão do fogo aumentou esse parâmetro nas duas áreas. 


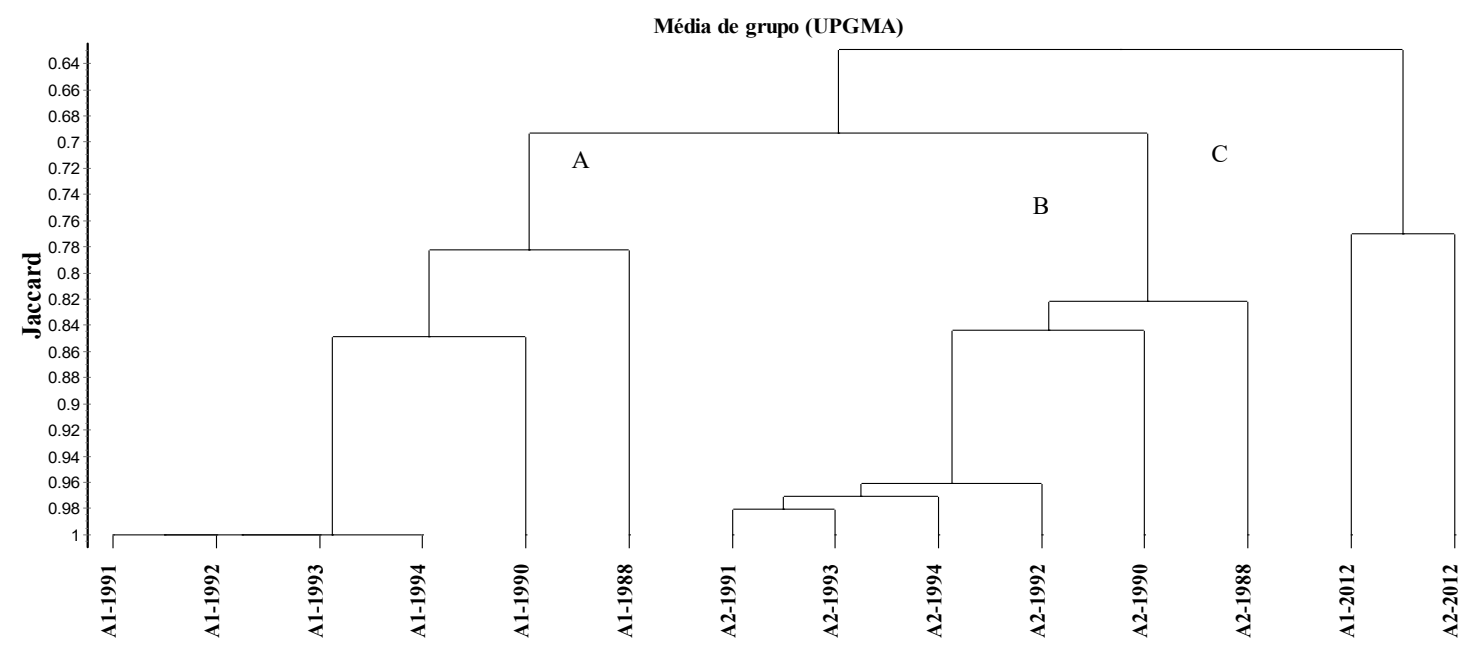

FIGURA 2: Dendrograma de similaridade pelo método UPGMA, pelo índice de Jaccard, entre duas áreas de Cerrado sentido restrito, em Planaltina - DF, de 1988 a 2012. Em que: A = Área 1, com queimadas bienais de 1988 a 1992; B = Área 2, protegida do fogo de 1988 a julho de 1994; C = Área 1 e Área 2, protegidas do fogo de setembro de 1994 a 2012; A1 = Área 1; A2 = Área 2. Correlação cofenética $=0,9807$.

FIGURE 2: Cluster Analysis Dendrogram (UPGMA) based upon Jaccard's Index in two areas of Cerrado sensu stricto in Planaltina, Federal District, Brazil from 1988 to 2012. Where: A = Area 1, fire was set from 1988 to 1992; B =Area 2 was protected against fire from 1988 to July 1994; C = Area 1 and Area 2, with protection against fire from September 1994 to 2012; A1 = Area 1; A2 = Area. Cophenetic correlation $=0.9807$.

A densidade estimada variou nas duas áreas, com diferenças significativas no período com queimadas bienais de 1988 a 1994 (p<0,05). Na Área 1, passou de 3280 ind./ha em 1988 para 1915 ind./ha em 1990 e 1950 ind./ha em 1994. Na Área 2, a densidade aumentou em todos os anos passando de 2545 ind./ha em 1988 para 4595 ind./ha em 1994. Em 2012 foram estimados 6440 ind./ha na Área 1 e 6030 ind./ha na Área 2. A densidade nas parcelas variou entre 1994 a 2012, com diferenças significativas $(p<0,05)$. No entanto, em 2012, não houve diferença entre as duas áreas ( $p>0,05)$. O acúmulo de biomassa na camada superficial do solo, principalmente gramíneas, aumenta a probabilidade de ignição, a intensidade e a extensão do fogo (CIANCIARUSO; SILVA; BATALHA, 2010), e dessa forma, em áreas protegidas, o risco de incêndios poderá ser maior e resultar em incêndios de maiores proporções (SILVA et al., 2011), justificando a maior perda em densidade com a queimada de 1988. No período de 1988 a 1994, houve uma redução de 40,5\% na densidade estimada da Área 1. Percentuais inferiores a esse, com redução de 30\%, foram observados em Cerrado sentido restrito na Fazenda Água Limpa, Distrito Federal, com três queimadas, em 12 anos (SILVA, 1999). Já, em Nova Xavantina (MT), uma redução de 17,5\% ocorreu em cinco anos, com duas queimadas (LIMA; LIMA; RATTER, 2009). Essas diferenças na redução da densidade da vegetação pelo fogo podem estar relacionadas à época, intensidade e frequência das queimadas (MIRANDA; NASCIMENTO NETO; NEVES, 2010), com o favorecimento de algumas espécies e exclusão de outras mais sensíveis (SILVA et al., 2011).

A área basal variou em todos os anos, nas duas áreas, com os seguintes valores $\mathrm{em} \mathrm{m}^{2} / \mathrm{ha}$ na Área 1: 8,48 (1990), 9,10 (1991), 9,52 (1992), 9,84 (1993), 9,27 (1994) e 18,85 (2012); e na Área 2: 9,54 (1990), 10,04 (1991), 11,01 (1992), 12,22 (1993), 11,99 (1994), 16,69 (2012). Houve diferenças significativas na área basal total/ha e na área basal média entre as duas áreas de 1990 a 1994 ( os maiores valores na Área 2. Na Reserva Ecológica do IBGE (Distrito Federal), resultados semelhantes foram encontrados por Ramos (1990), que constatou maior área basal de espécies arbóreas em uma área protegida por 13 anos, em relação a outra queimada a cada dois anos. As queimadas bienais frequentes influenciaram a área basal quando comparado à área sem fogo. No entanto, o fogo não reduziu a área basal da comunidade na Área 1 após a segunda queimada, quando os valores foram muito próximos de 1990 a 1994, provavelmente devido à maior mortalidade dos indivíduos mais finos, ou ao fato do crescimento radial ter sido capaz de repor a perda em área basal decorrente da mortalidade (LIMA; LIMA; RATTER, 2009). Dessa forma, o período de exclusão do fogo até 2012 favoreceu o aumento em área basal nas duas áreas 
$\left(18,85\right.$ e $\left.16,69 \mathrm{~m}^{2} / \mathrm{ha}\right)$, com valores maiores do que em outros trabalhos. No Distrito Federal, por exemplo, Andrade et al. (2002) encontraram área basal de 13,28 $\mathrm{m}^{2} /$ ha na Reserva Ecológica do IBGE, e, Assunção e Felfili (2004), de 9,53 na APA do Paranoá. Essas diferenças podem estar relacionadas à heterogeneidade florística frequentemente encontrada em Cerrado sentido restrito (CARVALHO et al., 2008), bem como à metodologia adotada na Embrapa Cerrados, que incluiu as famílias Arecaceae e Velloziaceae e indivíduos com diâmetro abaixo de $5 \mathrm{~cm}$.

Na Área 1, entre as dez espécies com maior IVI em 1990, nove se mantiveram durante o período de 1991 a 1994 (Tabela 2). Essas nove espécies tiveram variação no número de indivíduos e de IVI, mudando, assim, a posição na classificação com relação ao IVI no período de queimadas bienais. Em 2012, dessas nove espécies, três se mantiveram entre as dez com maior IVI. Em 1990, as dez espécies com maior IVI correspondiam a 51,7\% do total; em 1994, correspondiam a 53,1\%; em 2012, 13 espécies correspondiam a 51,1\%. Em 1990, Vellozia squamata Pohl foi a espécie com maior IVI principalmente devido a sua dominância. Ouratea hexasperma (A.St.-Hil.) Baill. teve maior IVI de 1991 a 1994, devido à maior densidade, e também esteve entre as mais importantes no Jardim Botânico de Brasília - DF (MIRANDA; SILVA JUNIOR; CARVALHO, 2013). Tachigali subvelutina (Benth.) Oliveira-Filho estava na oitava posição em 1990, e foi a espécie com maior IVI em 2012, em razão da dominância. As queimadas frequentes tendem a reduzir a densidade de plantas lenhosas, podendo favorecer algumas espécies (LIMA; LIMA; RATTER, 2009). Tachigali subvelutina parece ser resistente ao fogo e, por outro lado, Myrsine guianensis (Aubl.) Kuntze e Guapira graciliflora (Mart. ex Schmidt) Lundell parecem ser resilientes, pois tinham poucos indivíduos durante as queimadas e, depois, tornaram-se mais abundantes no período sem fogo. Na Área 2, das dez espécies com maior IVI em 1990, sete se mantiveram no período de 1991 a 1994, mas com variação na densidade, mudando, assim, a posição com relação ao IVI. Em 2012, dessas sete, seis permaneceram entre as dez espécies com maior IVI. Em todos os anos, as dez espécies com maior IVI representavam cerca de $50 \%$ do IVI total. Dalbergia miscollobium Benth. manteve-se na primeira posição até 1991, devido à maior dominância. Myrsine guianensis, mencionada como espécie sensível ao fogo (SAMBUICHI, 1991), manteve-se na primeira posição, de 1992 a 1994, em razão da densidade, e em 2012, em razão da densidade e dominância.

TABELA 2: Índice de Valor de Importância (IVI) da vegetação arbóreo-arbustiva em duas áreas de Cerrado sentido restrito com diferentes históricos de fogo, em Planaltina - DF, em 6 ocasiões do monitoramento.

TABLE 2: Importance Value Index (IVI) of tree and shrub plants in two areas of Cerrado sensu stricto with different historical burnings in Planaltina, Federal District, Brazil, on six occasions.

\begin{tabular}{|c|c|c|c|c|c|c|c|c|c|c|c|c|}
\hline \multirow[t]{2}{*}{ Espécies } & \multicolumn{6}{|c|}{ Área 1} & \multicolumn{6}{|c|}{ Área 2} \\
\hline & 1 & 2 & 3 & 4 & 5 & 6 & 1 & 2 & 3 & 4 & 5 & 6 \\
\hline Aegiphila verticillata Vell. & 5,4 & 6,3 & 7,0 & 5,8 & 6,5 & & 8,1 & 8,5 & 8,2 & 7,7 & 7,4 & \\
\hline Andira humilis Mart. ex Benth. & & & & & & & 0,7 & 0,6 & 0,7 & 0,6 & 0,6 & \\
\hline Andira vermifuga (Mart.) Benth. & & & & & & & & & & & & 0,4 \\
\hline Annona crassiflora Mart. & 5,7 & 6,5 & 5,4 & 6,2 & 6,2 & 4,1 & & & & & & 0,7 \\
\hline Annona monticola Mart. & & 1,1 & 1,1 & 0,7 & 0,6 & 3,4 & 2,7 & 1,2 & 0,4 & 1,5 & 1,5 & 2,6 \\
\hline Annona tomentosa R.E.Fr. & & & & & & 7,5 & 0,4 & & & & & 7,4 \\
\hline Aspidosperma macrocarpum Mart. & 1,7 & 5,7 & 5,8 & 5,5 & 6,3 & 4,1 & 6,7 & 7,5 & 7,7 & 7,9 & 7,7 & 9,0 \\
\hline Aspidosperma tomentosum Mart. & 7,2 & 3,3 & 3,7 & 3,1 & 2,9 & 4,1 & 6,3 & 6,4 & 6,3 & 6,5 & 6,5 & 8,3 \\
\hline Bauhinia dumosa Benth. & & & & & & 3,4 & 3,9 & & & & & 4,8 \\
\hline Bauhinia rufa (Bong.) Steud. & & & & & & 0,8 & & & & & & 0,6 \\
\hline Brosimum gaudichaudii Trécul & 0,7 & 0,6 & 0,5 & & & 0,9 & 0,4 & & & & & 0,3 \\
\hline Butia leiospatha (Barb.Rodr.) Becc. & & & & & & & 1,0 & 0,8 & 0,9 & 0,9 & & \\
\hline Byrsonima basiloba A.Juss. & & & & & & 0,7 & 0,4 & & & & & \\
\hline Byrsonima coccolobifolia Kunth & 2,2 & 2,0 & 2,1 & 2,3 & 2,2 & 2,7 & 0,6 & 1,0 & 1,4 & 1,4 & 1,4 & 2,5 \\
\hline Byrsonima verbascifolia (L.) DC. ${ }^{1}$ & 12,8 & 10,7 & 10,4 & 12,9 & 13,3 & 2,9 & 11,1 & 11,2 & 11,0 & 10,7 & 10,5 & 3,4 \\
\hline Caryocar brasiliense Cambess. & 7,0 & 7,5 & 7,1 & 6,3 & 6,1 & 8,0 & 3,9 & 4,3 & 4,3 & 3,7 & 3,7 & 5,6 \\
\hline $\begin{array}{l}\text { Casearia sylvestris } \mathrm{Sw} . \\
\text { Chomelia ribesioides Benth. ex }\end{array}$ & 0,7 & 0,6 & 0,6 & & 0,7 & 0,3 & 1,8 & 1,7 & 1,7 & 1,6 & 1,6 & 0,3 \\
\hline A.Gray & & & & & & 1,3 & 2,6 & 2,2 & 1,2 & 2,3 & 2,2 & 0,6 \\
\hline Connarus suberosus Planch. & 9,4 & 8,6 & 8,2 & 9,3 & 9,2 & 6,3 & 6,5 & 6,9 & 6,9 & 6,1 & 6,0 & 2,8 \\
\hline Cordiera sessilis (Vell.) Kuntze & & & & & & 2,5 & & & & & & 0,3 \\
\hline
\end{tabular}


TABELA 2: Continuação...

TABLE 2: Continued...

\begin{tabular}{|c|c|c|c|c|c|c|c|c|c|c|c|c|}
\hline \multirow[t]{2}{*}{ Espécies } & \multicolumn{6}{|c|}{ Área 1} & \multicolumn{6}{|c|}{ Área 2} \\
\hline & 1 & 2 & 3 & 4 & 5 & 6 & 1 & 2 & 3 & 4 & 5 & 6 \\
\hline $\begin{array}{l}\text { Cybianthus gardneri (A.DC.) } \\
\text { G.Agostini }\end{array}$ & & & & & & 1,4 & & & & & & 0,3 \\
\hline $\begin{array}{l}\text { Dalbergia miscolobium Benth. } \\
\text { Davilla elliptica } \text { A.St.-Hil. }\end{array}$ & 13,6 & 13,2 & 13,4 & 14,4 & 11,9 & 6,8 & $\begin{array}{c}27,3 \\
0,4\end{array}$ & 28,7 & 28,1 & 27,0 & 26,5 & 21,8 \\
\hline Dimorphandra mollis Benth. & 4,2 & 7,0 & 6,6 & 4,6 & 5,1 & 2,4 & 6,6 & 7,4 & 6,9 & 6,5 & 7,0 & 4,1 \\
\hline $\begin{array}{l}\text { Diospyros burchellii Hiern. } \\
\text { Enterolobium gummiferum (Mart.) }\end{array}$ & 0,7 & & & & & 0,9 & 1,1 & 1,1 & 1,1 & 1,4 & 1,6 & 1,0 \\
\hline $\begin{array}{l}\text { J.F.Macbr. } \\
\text { Eremanthus goyazensis (Gardner) }\end{array}$ & & & & & & 1,2 & & & & & & 0,3 \\
\hline $\begin{array}{l}\text { Sch.Bip. } \\
\text { Eriotheca pubescens (Mart. \& }\end{array}$ & & & & & & 0,3 & 3,1 & 3,0 & 3,6 & 3,4 & 3,7 & 1,1 \\
\hline Zucc.) Schott \& Endl. & 1,0 & 2,2 & 2,1 & 2,5 & 2,4 & 2,5 & 1,6 & 1,6 & 1,5 & 1,5 & 1,5 & 1,5 \\
\hline Erythroxylum campestre A.St.-Hil. & 3,8 & 1,2 & 1,2 & & & & & & & & & \\
\hline Erythroxylum deciduum A.St.-Hil. & 1,7 & 3,3 & 3,2 & 3,5 & 3,7 & 5,3 & 2,0 & 3,4 & 3,4 & 3,2 & 3,5 & 4,7 \\
\hline Erythroxylum suberosum A.St.-Hil. & & 4,1 & 3,9 & 3,7 & 3,6 & 1,7 & 4,3 & 7,2 & 7,0 & 6,4 & 6,2 & 2,9 \\
\hline Erythroxylum tortuosum Mart. & 0,7 & & & & & 0,3 & 2,9 & & & & & \\
\hline $\begin{array}{l}\text { Esenbeckia pumila Pohl } \\
\text { Guapira graciliflora (Mart. ex }\end{array}$ & & & & & & 1,1 & & & & & & \\
\hline Schmidt) Lundell & 2,5 & 3,1 & 5,7 & 1,5 & 3,0 & 22,4 & 11,7 & 9,9 & 9,5 & 10,1 & 10,0 & 10,6 \\
\hline Guapira noxia (Netto) Lundell ${ }^{1}$ & 15,6 & 14,8 & 13,3 & 10,4 & 11,7 & 6,8 & 20,0 & 20,0 & 19,5 & 18,9 & 18,7 & 11,0 \\
\hline $\begin{array}{l}\text { Hancornia speciosa Gomes } \\
\text { Handroanthus ochraceus (Cham.) }\end{array}$ & & 0,6 & 0,6 & 0,7 & 0,7 & 0,3 & & & & & & \\
\hline Mattos & 7,5 & 7,2 & 7,8 & 8,5 & 7,8 & 2,8 & 5,4 & 5,9 & 6,2 & 6,6 & 6,3 & 2,4 \\
\hline $\begin{array}{l}\text { Heteropterys byrsonimifolia A.Juss. } \\
\text { Hymenaea stigonocarpa Mart. ex }\end{array}$ & & & & & & 2,7 & & & & & & 1,1 \\
\hline Hayne & 5,5 & 4,8 & 5,1 & 6,1 & 5,9 & 2,9 & 6,2 & 6,4 & 6,3 & 5,7 & 5,7 & 4,0 \\
\hline Kielmeyera coriacea Mart. \& Zucc. & 4,8 & 4,0 & 4,4 & 5,1 & 3,9 & 8,8 & 7,3 & 9,3 & 9,2 & 9,4 & 8,8 & 5,8 \\
\hline Kielmeyera speciosa A.St.-Hil. & & & & & & 0,3 & & & & & & \\
\hline Leptolobium dasycarpum Vogel & 6,8 & 6,5 & 5,9 & 6,5 & 5,7 & 5,9 & 6,7 & 6,7 & 6,8 & 6,5 & 7,0 & 6,2 \\
\hline Machaerium acutifolium Vogel & & & & & & 1,1 & & & & & & \\
\hline Machaerium opacum Vogel & 8,6 & 6,3 & 6,5 & 5,8 & 5,8 & 8,6 & 2,5 & 2,0 & 2,0 & 1,5 & 1,9 & 2,6 \\
\hline Maprounea guianensis Aubl. & & & & & & 1,8 & & & & & & 0,3 \\
\hline Miconia albicans (Sw.) Triana & & & & & & 3,9 & & & & & & 8,1 \\
\hline Miconia burchellii Triana & & & & & & 6,1 & & & & & & 4,6 \\
\hline Miconia fallax DC. & 2,7 & 1,9 & 1,8 & 2,0 & 1,9 & 1,2 & & & & & & 5,5 \\
\hline Miconia ferruginata DC. & & & & & & & & & & & & 0,4 \\
\hline Mimosa claussenii Benth. & 3,4 & 3,1 & 3,0 & 1,5 & 0,8 & 0,9 & 2,9 & 0,9 & 1,1 & 0,8 & 1,0 & 3,6 \\
\hline Myrsine guianensis (Aubl.) Kuntze & 2,7 & 4,7 & 5,5 & & 0,6 & 19,6 & 25,1 & 26,5 & 28,2 & 30,6 & 30,1 & 54,2 \\
\hline Neea theifera Oerst. & & 2,3 & 2,7 & 2,0 & 2,0 & 5,6 & 7,4 & 9,4 & 9,8 & 10,2 & 9,9 & 0,7 \\
\hline $\begin{array}{l}\text { NI - Lauraceae } \\
\text { Ouratea hexasperma (A.St.-Hil.) }\end{array}$ & & & & & & & & & & & & 0,5 \\
\hline Baill. $^{1}$ & 21,3 & 22,0 & 20,9 & 24,6 & 23,8 & 11,4 & 16,7 & 15,4 & 14,9 & 14,0 & 13,5 & 10,8 \\
\hline $\begin{array}{l}\text { Palicourea rigida Kunth } \\
\text { Piptocarpha rotundifolia (Less.) }\end{array}$ & 2,5 & 1,5 & 1,4 & 1,6 & 0,6 & 6,2 & 3,5 & 5,5 & 5,5 & 7,4 & 7,3 & 8,8 \\
\hline Baker & 4,1 & 3,6 & 3,4 & 3,9 & 4,8 & 4,2 & 4,2 & 3,5 & 3,4 & 3,4 & 3,1 & 4,6 \\
\hline Plathymenia reticulata Benth. & 1,5 & 2,1 & 1,4 & & 1,7 & 0,6 & 0,4 & 0,5 & 0,4 & 0,4 & 0,4 & \\
\hline Plenckia populnea Reissek & 5,5 & 8,5 & 11,0 & 9,4 & 9,1 & 5,7 & 2,1 & 1,8 & 2,1 & 2,4 & 2,4 & 1,3 \\
\hline Pouteria ramiflora (Mart.) Radlk. & 3,6 & 3,1 & 2,9 & 3,5 & 3,4 & 2,1 & 1,2 & 1,2 & 1,2 & 1,1 & 1,1 & 0,8 \\
\hline Protium ovatum Engl. & & & & & & 5,5 & 3,8 & 1,4 & 1,8 & 2,2 & 2,1 & 8,2 \\
\hline Psidium laruotteanum Cambess. & 2,1 & 2,8 & 3,2 & 3,6 & 2,7 & 3,3 & 3,7 & 3,4 & 3,8 & 3,8 & 3,7 & 2,1 \\
\hline Qualea grandiflora Mart. & & & & & & & & & & & & 0,5 \\
\hline Qualea multiflora Mart. & 2,1 & 1,8 & 1,9 & 1,9 & 1,9 & & & & & & & \\
\hline Qualea parviflora Mart. & & & & & & 2,6 & & & & & & \\
\hline Roupala montana Aubl. & 3,1 & 2,7 & 3,7 & 2,2 & 2,2 & 10,2 & 4,8 & 6,0 & 6,0 & 6,5 & 6,4 & 11,0 \\
\hline
\end{tabular}

Continuação... 
TABELA 2: Continuação...

TABLE 2: Continued..

\begin{tabular}{|c|c|c|c|c|c|c|c|c|c|c|c|c|}
\hline \multirow[t]{2}{*}{ Espécies } & \multicolumn{6}{|c|}{ Área 1} & \multicolumn{6}{|c|}{ Área 2} \\
\hline & 1 & 2 & 3 & 4 & 5 & 6 & 1 & 2 & 3 & 4 & 5 & 6 \\
\hline $\begin{array}{l}\text { Salacia crassifolia (Mart. ex } \\
\text { Schult.) G.Don }\end{array}$ & 1,4 & & & & & & & & & 0,4 & 0,4 & 0,7 \\
\hline $\begin{array}{l}\text { Salvertia convallariodora A.St.-Hil. } \\
\text { Schefflera macrocarpa (Cham. \& }\end{array}$ & & & & & & & 1,9 & 1,8 & 1,7 & 1,6 & 1,6 & 2,1 \\
\hline $\begin{array}{l}\text { Schltdl.) Frodin }{ }^{1} \\
\text { Senna rugosa (G.Don) H.S.Irwin \& } \\
\text { Barneby }\end{array}$ & 9,5 & 8,7 & 8,3 & 9,6 & 9,4 & $\begin{array}{l}6,7 \\
0,3\end{array}$ & 2,1 & 1,9 & 2,0 & 1,4 & 2,0 & 6,5 \\
\hline $\begin{array}{l}\text { Strychnos pseudoquina A.St.-Hil. } \\
\text { Stryphnodendron adstringens }\end{array}$ & 5,3 & 4,3 & 3,0 & 3,2 & 3,1 & 2,9 & 2,6 & 4,0 & 3,9 & 3,7 & 3,6 & 3,7 \\
\hline (Mart.) Coville & 4,5 & 5,0 & 4,8 & 5,3 & 5,2 & 7,8 & 4,0 & 4,1 & 3,9 & 3,5 & 3,8 & 4,8 \\
\hline Styrax ferrugineus Nees \& Mart. ${ }^{1}$ & 17,9 & 18,1 & 20,8 & 19,1 & 18,9 & 13,3 & 17,8 & 16,5 & 16,7 & 16,9 & 17,3 & 8,8 \\
\hline Syagrus flexuosa (Mart.) Becc. ${ }^{1}$ & 20,3 & 18,3 & 17,6 & 23,3 & 22,2 & 2,0 & 4,9 & 7,7 & 7,9 & 7,6 & 8,7 & 2,1 \\
\hline Syagrus oleracea (Mart.) Becc. & & & & & & & & 0,7 & 0,9 & 0,9 & 0,9 & \\
\hline $\begin{array}{l}\text { Symplocos rhamnifolia A.DC. } \\
\text { Tachigali subvelutina (Benth.) }\end{array}$ & 4,6 & 4,1 & 3,9 & 4,3 & 4,4 & & & & & & & \\
\hline Oliveira-Filho & 12,1 & 13,2 & 14,7 & 16,0 & 16,9 & 23,0 & 3,3 & 3,5 & 3,7 & 3,9 & 4,1 & 6,7 \\
\hline $\begin{array}{l}\text { Terminalia fagifolia Mart. } \\
\text { Tocoyena formosa (Cham. \& }\end{array}$ & & & & & & 0,6 & & & & & & \\
\hline Schltdl.) K.Schum. & 1,0 & 2,9 & 2,5 & 2,4 & 3,6 & 0,6 & 0,9 & 0,4 & & 0,8 & 0,9 & 0,3 \\
\hline Vellozia squamata Pohl ${ }^{1}$ & 21,6 & 21,0 & 17,5 & 21,6 & 22,1 & 3,6 & 15,4 & 15,5 & 15,9 & 13,9 & 14,7 & 3,8 \\
\hline Vochysia elliptica Mart. ${ }^{1}$ & 10,4 & 8,0 & 8,3 & 7,9 & 7,9 & 3,8 & 2,5 & 2,5 & 2,5 & 2,8 & 2,7 & 2,2 \\
\hline Vochysia thyrsoidea Pohl & 6,2 & 5,6 & 4,3 & 5,9 & 5,6 & 4,2 & & & & & & \\
\hline Zeyheria montana Mart. & 1,4 & & & & & 0,8 & 1,5 & 1,5 & 1,5 & 1,4 & 1,4 & 1,3 \\
\hline Total & 300 & 300 & 300 & 300 & 300 & 300 & 300 & 300 & 300 & 300 & 300 & 300 \\
\hline
\end{tabular}

Em que: 1 = Espécies com maior IVI em 1990 na Área 1; Ocasiões do monitoramento: $1=1990,2=1991,3=1992$, $4=1993,5=1994,6$ = 2012; Área 1= com queimadas bienais em agosto de 1988, 1990 e 1992; Área 2 = protegida do fogo de 1988 a julho de 1994; e proteção das duas áreas de setembro de 1994 a 2012.

Nas duas áreas e em todo período do estudo, as distribuições dos indivíduos vivos em classes de altura não diferiram significativamente $(\mathrm{p}>0,05)$ (Figura 3). $\mathrm{Na}$ área 1 , em todos os anos, houve maior número de indivíduos na segunda classe de altura $(1,2-2,4 \mathrm{~m})$ em comparação à primeira $(0-1,2 \mathrm{~m})$, indicando que, mesmo com as queimadas, algumas espécies da primeira classe não foram atingidas pelo distúrbio e alcançaram a próxima classe.
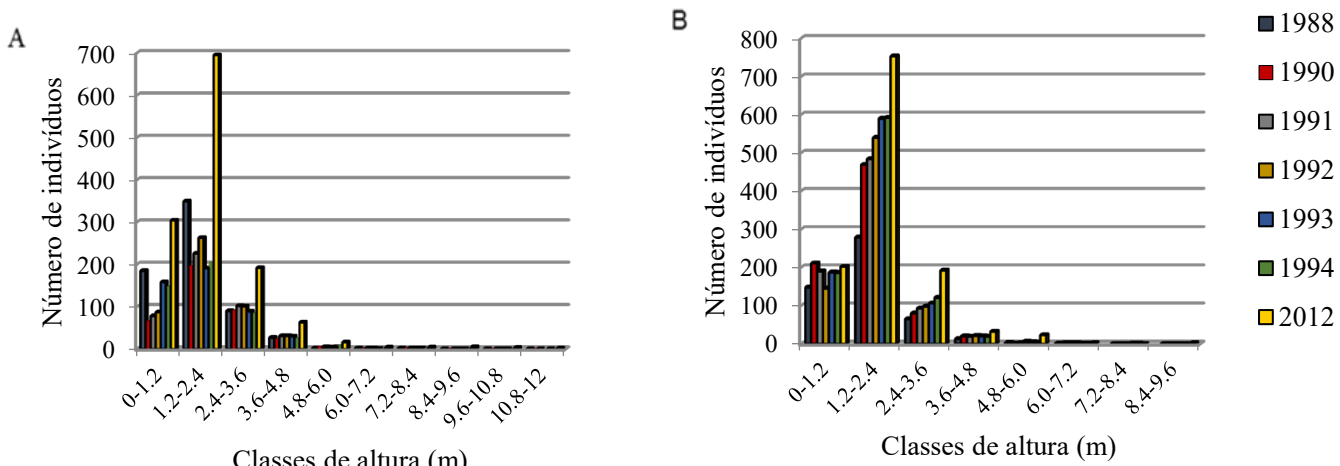

FIGURA 3: Distribuição dos indivíduos arbóreo-arbustivos vivos em classes de altura em duas áreas de Cerrado sentido restrito com diferentes históricos de fogo, em Planaltina - DF, de 1988 a 2012. Em que: A = Área 1, com três queimadas bienais de 1988 a 1992; B = Área 2, protegida do fogo de 1988 a julho de 1994; e proteção das duas áreas de setembro de 1994 a 2012.

FIGURE 3: Distribution of trees and shrub plants in height classes in two areas of Cerrado sensu stricto with different historical burnings in Planaltina, Federal District, Brazil. Fire was set in Area 1 in 1988, 1990 and 1992. Where: A = Area 1, fire was set in 1988, 1990 and 1992; B = Area 2, was protected against fire from 1988 to July 1994; and both areas were protected against fire from September 1994 to 2012 . 
Antes da primeira queimada, havia um elevado número de indivíduos nas duas primeiras classes (81\%), porém houve redução em 1990 e 1991 para 68\%, sugerindo que o fogo afetou os indivíduos menores. De 1992 a 1994, houve aumento nas duas primeiras classes. Mas, em 1993 e 1994, alguns indivíduos perderam a parte aérea e rebrotaram na base, reduzindo os percentuais na segunda e terceira classes. O calor desprendido pelo fogo, durante as queimadas, pode ter causado tanto danos nos indivíduos menores quanto nos indivíduos maiores, que tiveram danos na parte aérea. Esses indivíduos, possivelmente, não recuperaram a parte vegetativa tão rapidamente como acontece com os menores (HOFFMANN; SOLBRIG, 2003; MEDEIROS; MIRANDA, 2005) e apresentaram menor crescimento, não passando para a classe seguinte. Além disso, os possíveis danos nas plântulas e indivíduos jovens, relacionados às queimadas, podem ter limitado o desenvolvimento (SATO et al., 2010) daqueles nas menores classes de altura. Dessa forma, o aumento na primeira classe pode ter sido em função das espécies que rebrotaram, dos indivíduos novos (recrutas) que atingiram um metro de altura, após as queimadas, e daqueles que sobreviveram ao distúrbio, mas tiveram danos na parte aérea e não se estabeleceram na classe seguinte. Na Área 2, o aumento no número de indivíduos, na segunda, terceira e quarta classes, de 1988 a 1994, mostra que, com a exclusão do fogo, alguns indivíduos atingem alturas maiores e migram para classes superiores. Na primeira classe, o decréscimo dos indivíduos em alguns anos esteve, provavelmente, relacionado ao recrutamento para a classe superior e o acréscimo, aos indivíduos que atingiram a altura de um metro. De 1988 a 1994, e em 2012, cerca de $80 \%$ dos indivíduos ficaram concentrados nas duas primeiras classes, ou seja, com até 2,4 metros. E, em 2012, nas duas áreas, o número de indivíduos aumentou em todas as classes, com cerca de $95 \%$ com até 3,6 m, demonstrando que são de pequeno porte. No Distrito Federal, em Cerrado sentido restrito com indicativos de distúrbios pela pressão antrópica do entorno, Assunção e Felfili (2004) também registraram grande percentual de indivíduos jovens, sendo mais de 59\% com altura inferior a quatro metros.

As distribuições dos indivíduos vivos em classes de diâmetro não diferiram nas duas áreas, de 1990 a 2012 (p>0,05) (Figura 4), e apresentaram curva com padrão de distribuição "j" invertido, comumente encontrado em comunidades em processo de regeneração e recrutamento, nas quais há maior concentração dos indivíduos na menor classe (ASSUNÇÃO; FELFILI, 2004; MIRANDA; SILVAJUNIOR; CARVALHO, 2013).

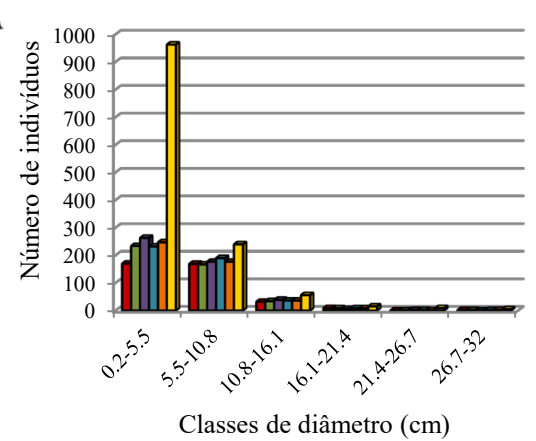

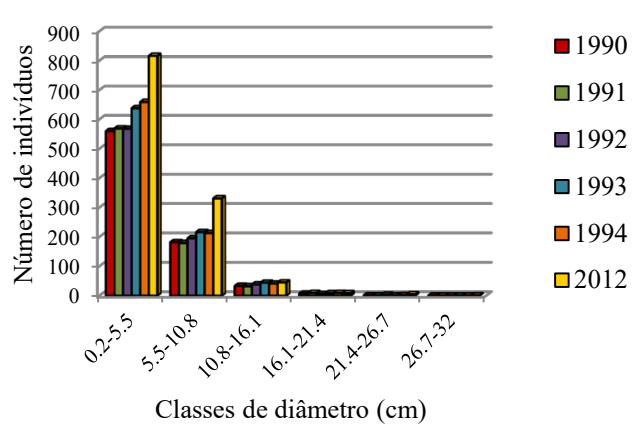

FIGURA 4: Distribuição dos indivíduos arbóreo-arbustivos vivos em classes de diâmetro em duas áreas de Cerrado sentido restrito com diferentes históricos de fogo, em Planaltina - DF, de 1990 a 2012. Em que: A= Área 1, com três queimadas bienais de 1988 a 1992; B = Área 2, protegida do fogo de 1988 a julho de 1994; e proteção das duas áreas de setembro de 1994 a 2012.

FIGURE 4: Distribution of trees and shrubs plants in diameter classes in two areas of Cerrado sensu stricto with different historical burnings in Planaltina, Federal District, Brazil. Where: A= Area 1, fire was set in 1988, 1990 and 1992; B = Area 2, was protected against fire from 1988 to July 1994; and both areas were protected against fire from September 1994 to 2012.

Na Área 1, o aumento da frequência relativa na primeira classe, em 1991, um ano após a segunda queimada, possivelmente esteve relacionado ao estímulo, provocado pelo fogo, da floração e produção de sementes (SILVA et al., 2011), ao desenvolvimento de novos indivíduos a partir das sementes que sobreviveram à passagem do fogo, à sobrevivência das plântulas mais tolerantes (ANDRADE; MIRANDA, 2010), bem como à capacidade de rebrota de algumas espécies (COUTINHO, 1990). Após a terceira queimada de 1992 e com a mortalidade de algumas plantas, em 1993 houve redução de indivíduos na 
primeira classe de diâmetro. A maior mortalidade após o fogo, de forma geral, está associada aos indivíduos nas menores classes de diâmetro, como foi visto em Cerrado sentido restrito, na Fazenda Água Limpa (DF), por Fiedler et al. (2004), e em Campo sujo, na Reserva Ecológica do IBGE (DF) por Medeiros e Miranda (2005). Em 1994 também houve redução dos indivíduos na segunda classe, possivelmente, devido aos danos causados pelas três queimadas terem fragilizado algumas plantas, levando à mortalidade em anos posteriores. Porém, em 2012, o número de indivíduos aumentou na primeira classe nas duas áreas, indicando o favorecimento de algumas espécies e que a comunidade ainda está em processo de regeneração. Resultados semelhantes, com maior concentração de indivíduos na primeira classe de diâmetro (até $5 \mathrm{~cm}$ ) foram observados em Campo sujo na Reserva Ecológica do IBGE (DF), 23 anos sem queimar (MEDEIROS; MIRANDA, 2005). Na Reserva da Embrapa Cerrados, possivelmente, o pastejo esporádico de gado bovino e a pressão antrópica do entorno também podem ter influenciado os resultados, principalmente na Área 2.

\section{CONCLUSÕES}

O monitoramento, durante o período com queimadas bienais de 1988 a 1994, e após 18 anos de proteção, em 2012, evidenciou mudanças com relação à composição florística e à estrutura da comunidade da vegetação arbóreo-arbustiva. A comunidade mostrou-se resistente e resiliente ao fogo, visto que muitas espécies se mantiveram na área durante todo o período de monitoramento, e que a exclusão do distúrbio favoreceu a entrada de espécies, bem como incrementos em densidade e área basal. As duas áreas com distintos históricos de fogo não apresentaram diferenças na riqueza, porém, mostraram diferenças na similaridade florística e na diversidade no período de 1988 a 1994. A exclusão do fogo por 18 anos favoreceu a similaridade florística entre as duas áreas e, por outro lado, proporcionou diferenças na diversidade, sendo maior na Área 1. As duas áreas apresentaram diferenças na densidade e área basal em todo o período de estudo. As queimadas bienais reduziram a densidade e a área basal, e a exclusão do fogo por 18 anos proporcionou o aumento em densidade e área basal. As duas áreas não mostraram diferenças na distribuição dos indivíduos vivos em classes de altura e diâmetro, em todo o período do monitoramento. No entanto, a incidência de queimadas bienais afetou, principalmente, os indivíduos nas menores classes de altura e diâmetro.

\section{REFERÊNCIAS}

ALMEIDA, R. F. et al. Mudanças florísticas e estruturais no cerrado sensu stricto ao longo de 27 anos (1985-2012) na Fazenda Água Limpa, Brasília, DF. Rodriguésia, Rio de Janeiro, v. 65, n. 1, p. 1-19, 2014. ANDRADE, L. A. Z. et al. Fitossociologia de uma área de cerrado denso na RECOR-IBGE, Brasília-DF. Acta Botanica Brasilica, Belo Horizonte, v. 16, n. 2, p. 225-240, 2002.

ANDRADE, L. A. Z.; MIRANDA, H. S. O fator fogo no banco de sementes. In: MIRANDA, H. S. (Org.). Efeitos do fogo sobre a estrutura de comunidades de Cerrado: resultados do Projeto Fogo. Brasília: IBAMA, 2010. p. 103-119.

ASSUNÇÃO, S.; FELFILI, J. M. Fitossociologia de um fragmento de cerrado sensu stricto na APA do Paranoá, DF. Brasil. Acta Botanica Brasilica, Belo Horizonte, v. 18, p. 903-909, 2004.

CAMARGOS, V. L. et al. Estudo do comportamento do fogo em um trecho de floresta estacional semidecídua no município de Viçosa, Minas Gerais. Ciência Florestal, Santa Maria, v. 25, n. 3, p. 537-545, 2015.

CARVALHO, F. A. et al. Composição florística, riqueza e diversidade de um cerrado sensu stricto no sudeste do estado de Goiás. Bioscience Journal, Uberlândia, v. 24, n. 4, p. 64-72, 2008.

CHASE, M. W.; REVEAL, J. L. A phylogenetic classification of the land plants to accompany APG III. Botanical Journal of the Linnean Society, London, v. 161, p. 122-127, 2009.

CIANCIARUSO, M. V.; SILVA, I. A.; BATALHA, M. A. Aboveground biomass of functional groups in the ground layer of savannas under different fire frequencies. Australian Journal of Botany, Melbourne, v. 58, n. 3, p. 169-174, 2010.

CIRNE, P.; MIRANDA, H. S. Effects of prescribed fires on the survival and release of seeds of Kielmeyera coriacea (Spr.) Mart. (Clusiaceae) in savannas of Central Brazil. Brazilian Journal of Plant Physiology, Londrina, v. 20, n. 3, p. 197-204, 2008. 
COUTINHO, L. M. Fire in the ecology of the Brazilian cerrado. In: GOLDAMMER, J. G. (Ed.). Fire in the Tropical Biota. Berlin: Springer-Verlag, 1990. p. 82-105.

FELFILI, J. M. et al. Changes in the floristic composition of cerrado sensu stricto in Brazil over a nine-year period. Journal of Tropical Ecology, Cambridge, v. 16, p. 579-590, 2000.

FELFILI, J. M.; REZENDE, R. P. Conceitos e métodos em fitossociologia. Brasília: Universidade de Brasília, 2003. (Comunicações técnicas, n. 1).

FIEDLER, N. C. et al. Efeito de Incêndios Florestais na Estrutura e Composição Florística de uma Área de Cerrado Sensu Stricto na Fazenda Água Limpa-DF. Revista Árvore, Viçosa, v. 28, n.1, p. 129-138, 2004.

HAMMER, O.; HARPE, A. T. D.; RYAN, P. D. PAST: Paleontological statistics software package for education and data analysis. Paleontologia Eletronica, Oslo, v. 4, n. 1, p. 1-9, 2001.

HENRIQUES, R. P. B. Influência da história, solo e fogo na distribuição e dinâmica das fitofisionomias no bioma Cerrado. In: SCARIOT, A.; SOUSA-SILVA, J. C.; FELFILI, J. M. (Org.). Cerrado: ecologia, biodiversidade e conservação. Brasília: MMA, 2005. p. 73-92.

HENRIQUES, R. P. B.; HAY, J. D. Patterns and dynamics of plant population. In: OLIVEIRA, P. S.; MARQUIS, R. J. The Cerrados of Brazil: ecology and natural history of a neotropical savanna. New York: Columbia University Press, 2002. p. 140-158.

HOFFMANN, W. A. The effects of fire and cover on seedling establishment in a Neotropical Savanna. Journal of Ecology, Oxford, v. 84, n. 3, p. 383-393, 1996.

HOFFMANN, W. A.; SOLBRIG, O. T. The role of topkill in the differential response of savanna woody species to fire. Forest Ecology and Management, Wageningen, v. 180, p. 273-286, 2003.

JARDIM BOTÂNICO DO RIO DE JANEIRO. Lista de espécies da flora do Brasil. Rio de Janeiro: Jardim Botânico do Rio de Janeiro, 2005. Disponível em: <http://floradobrasil.jbrj.gov.br/>. Acesso em: dez. 2015.

LEINSTER, T.; COBBOLD, C. A. Measuring diversity: the importance of species similarity. Ecology, Washington, v. 93, n. 3, p. 477-489, 2012.

LIBANO, A. M.; FELFILI, J. M. Mudanças temporais na composição florística e na diversidade de um cerrado sensu stricto do Brasil Central em um período de 18 anos (1985-2003). Acta Botanica Brasílica, Belo Horizonte, v. 20, n. 4, p. 927-936, 2006.

LIMA, E. S.; LIMA, H. S.; RATTER, J. A. mudanças pós-fogo na estrutura e composição da vegetação lenhosa em um cerrado mesotrófico, no período de cinco anos (1997-2002) em Nova Xavantina - MT. Cerne, Lavras, v. 15, n. 4, p. 468-480, 2009.

MEDEIROS, M. B.; MIRANDA, H. S. Mortalidade pós-fogo em espécies lenhosas de campo sujo submetido a três queimadas prescritas anuais. Acta Botanica Brasilica, Belo Horizonte, v. 19, n. 3, p. 493-500, 2005. MEDEIROS, M. B.; MIRANDA, H. S. Post-fire resprouting and mortality in cerrado woody plant species over a three-year period. Edinburgh Journal of Botany, Edinburgh, v. 65, n. 1, p. 53-68, 2008.

MEDINA, E.; SILVA, J. F. Savannas of northern South América: a steady state regulated by water-fire interactions on a background of low nutrient availability. Journal of Biogeography, Malden, v. 17, p. 403-413, 1990.

MIRANDA, H. S.; NASCIMENTO NETO, W.; NEVES, B. M. C. Caracterização das queimadas no Cerrado. In: MIRANDA, H. S. (Org.). Efeitos do regime do fogo sobre a estrutura de comunidade de Cerrado: Projeto fogo. Brasília: IBAMA, 2010. p. 23-33.

MIRANDA, S. C.; SILVA JUNIOR, M. C.; CARVALHO, P. S. O efeito da proteção do fogo na estrutura da vegetação lenhosa de uma área de Cerrado sentido restrito no Brasil. Heringeriana, Brasília, v. 7, n. 1, p. 61-72, 2013.

MOREIRA, A. G. Effects of fire protection on savanna structure in Central Brazil. Journal of Biogeography, Malden, v. 27, p. 1021-1029, 2000.

MORO, M. F.; MARTINS, F. R. Métodos de levantamento do componente arbóreo-arbustivo. In: FELFILI, J. M. et al. Fitossociologia no Brasil: métodos e estudos de casos. Viçosa, MG: UFV, 2011. p. 174-212. MUELLER-DOMBOIS, D.; ELLENBERG, H. Aims and methods of vegetation ecology. New York: Willey and Sons, 1974.

PARRON, L. M. et al. Reservas ecológicas da Embrapa Cerrados: caracterização e zoneamento. Planaltina: EMBRAPA; CPAC, 1998. 80 p. 
PINHEIRO, E. S.; DURIGAN, G. Dinâmica espaço-temporal (1962-2006) das fitofisionomias em unidade de conservação do Cerrado no sudeste do Brasil. Revista Brasileira de Botânica, São Paulo, v. 32, n. 3, p. 441-454, 2009.

RAMOS, A. E. O efeito da queima sobre a vegetação lenhosa do cerrado. 1990. 142 f. Dissertação (Mestrado em Ecologia) - Universidade de Brasília, Brasília, 1990.

RIBEIRO, M. N. et al. Fogo e dinâmica da comunidade lenhosa em cerrado sentido restrito, Barra do Garças, Mato Grosso. Acta Botanica Brasilica, Belo Horizonte, v. 26, n. 1, p. 203-217, 2012.

SAMBUICHI, R. H. R. Efeitos de longo prazo do fogo periódico sobre a fitossociologia da camada lenhosa de um Cerrado em Brasília, DF. 1991. 129 f. Dissertação (Mestrado em Ecologia) - Universidade de Brasília, Brasília, 1991.

SATO, M. N. et al. O fogo e o estrato arbóreo do Cerrado: efeitos imediatos e de longo prazo. In: MIRANDA, H. S. (Org.). Efeitos do regime do fogo sobre a estrutura de comunidade de Cerrado: Projeto fogo. Brasília: IBAMA, 2010. p. 77-91.

SCARIOT, A. et al. Efeitos da fragmentação sobre os habitats. In: RAMBALDI, D. M; OLIVEIRA, D. A. S. (Org.). Fragmentação de ecossistemas. Brasília: MMA, 2003. p. 103-123.

SCOLFORO, J. R. S.; THIERSCH, C. R. Biometria florestal: medição, volumetria e gravimetria. Lavras: UFLA, 2004. 285 p.

SHEPHERD, G. J. Manual do usuário. FITOPAC 2.1.2.85 Campinas: UNICAMP, 2010.

SILVA, D. M. et al. Os efeitos dos regimes de fogo sobre a vegetação de Cerrado no Parque Nacional das Emas, GO: considerações para a conservação da diversidade. Biodiversidade Brasileira, Brasília, v. 1, n. 2, p. 26-39, 2011.

SILVA, M. A. Mudanças na composição florística e estrutura de um cerrado sensu stricto, em um período de 12 anos (1985- 1997), na Fazenda Água Limpa (FAL)-Brasília - DF. 1999. 62 f. Dissertação (Mestrado em Ciências Florestais) - Universidade de Brasília, Brasília, 1999.

SOKAL, R. R.; ROHLF, F. J. Introduction to Biostatistics. 2nd ed. New York: DOVER, 2009. 63 p.

SPERA, S. T. et al. Características físicas de um Latossolo Vermelho-Escuro, no Cerrado de Planaltina, DF, submetido à ação do fogo. Pesquisa Agropecuária Brasileira, Brasília, v. 35, n. 9, p. 1817-1824, 2000.

TÓTHMÉRÉSZ, B. Comparasion of different methods for diversity ordering. Journal of Vegetation Science, Malden, v. 6, p. 283-290, 1995.

VALENTIN, J. L. Ecologia numérica: uma introdução à análise multivariada de dados ecológicos. Rio de Janeiro: Interciência, 2000. 117 p.

ZAR, J. H. Biostatistical analysis. New Jersey: Prentice-Hall, 2009. 